\title{
Edukasi Pemanfaatan Limbah Sisa Makanan Menjadi Produk Yang Bernilai Ekonomis
}

\author{
Teuku Athaillah*1, Bagio ${ }^{2}$, Hasanuddin Husin ${ }^{3}$ \\ 1,2Program Studi Agribisnis Fakultas Pertanian Universitas Teuku Umar \\ ${ }^{3}$ Program Studi Teknologi Hasil Pertanian Fakultas Pertanian Universitas Teuku Umar \\ *e-mail: athaillah.teuku@utu.ac.id ${ }^{1}$, bagio@utu.ac.id² ${ }^{2}$ hasanuddinhusin@utu.ac.id ${ }^{3}$
}

\begin{abstract}
Poor waste management has become a problem in Kuta Jeumpa Village of Jeumpa Sub-district of Aceh Barat Daya Regency. The people of Kuta Jeumpa Village still throw their household wasteinto the river. As the result, the water of Putroe Aloh River in Kuta Jeumpa Village is filled with household waste. To overcome this situation, waste management education is needed to be carried out for the people of Kuta Jeumpa to manage their waste properly. The people of Kuta Jeumpa village need to be taught on how to turn waste into a source of income, for example by introducing on how to make processed food from household waste. After the the people of Kuta Jeumpa received the waste management education, they have succeeded in making new processed food products from household waste with the help of university students and lecturers. The products produced can provide profit value for the community. In addition, the community was also educated to no longer throw their household waste into the river.
\end{abstract}

Key words: household waste; Profit; food from waste.

\section{Abstrak}

Pengelolaan sampah kurang baik terjadi di Desa Kuta Jeumpa Kecamatan Jeumpa Kabupaten Aceh Barat Daya. Masyarakat Desa Kuta Jeumpa masih membuang sampah rumah tangga ke dalam sungai. Sungai Putroe Aloh yang berada di Desa Kuta Jeumpa tersebut dipenuhi dengan sampah rumah tangga dari masyarakat desa. Untuk mengatasi situasi tersebut, diperlukan edukasi terhadap warga kuta jeumpa untuk mengelola sampah dengan benar. Masyarakat desa Kuta Jeumpa perlu diajarkan untuk menjadikan sampah menjadi sumber pendapatan. Caranya dengan memperkenalkan kepada masyarakat cara membuat makanan olahan dari sampah rumah tangga. Masyarakat Kuta Jeumpa berhasil membuat produk baru dari hasil olahan limbah makanan yang dibimbing oleh mahasiswa bersama dosen. Produk yang dihasilkan tersebut bisa memberikan nilai profit bagi masyarakat. Masyarakat juga teredukasi tidak lagi membuang sampah ke sungai.

Kata kunci: Sampah; Profit; makanan dari limbah

\section{PENDAHULUAN}

Pengelolaan sampah yang kurang baik masih terjadi di Desa Kuta Jeumpa Kecamatan Jeumpa Kabupaten Aceh Barat Daya. Masyarakat Desa Kuta Jeumpa masih membuang sampah serta limbah rumah tangga ke dalam sungai. Sungai Putroe Aloh yang berada di Desa Kuta Jeumpa tersebut dipenuhi dengan sampah dan limbah rumah tangga dari masyarakat desa. Masyarakat Desa Kuta Jeumpa mengganggap pembuangan sampah dan limbah rumah tangga ke sungai sebagai hal yang biasa saja. Membuang sampah di sungai sudah dilakukan oleh masyarakat Desa Kuta Jeumpa sejak turun temurun. Masyarakat Desa Kuta Jeumpa juga sudah terbiasa menggunakan air sungai yang tercampur limbah untuk keperluan sehari-hari.
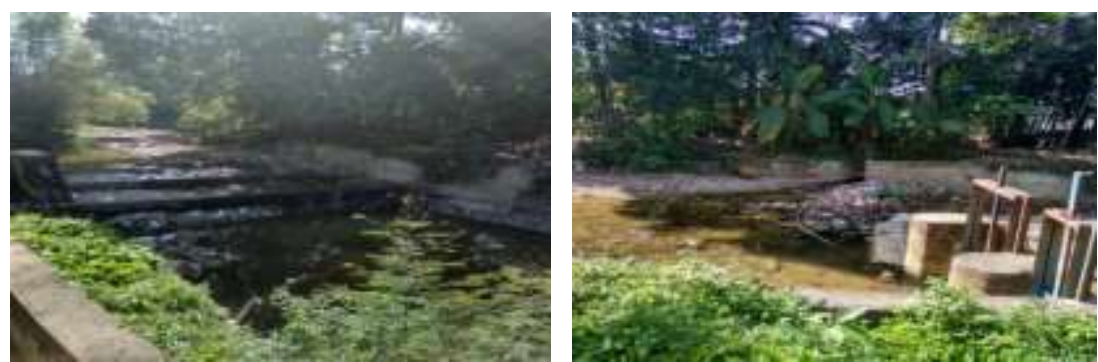

Gambar 1. Kondisi sungai Putroe Aloh di Gampong Kuta Jeumpa, Aceh Barat Daya 
Sampah yang menumpuk didalam sungai membuat aliran air menjadi tersendat. Gambar 1 menunjukkan banyaknya tumpukan sampah didalam sungai Putroe Aloh. Pemandangan sungai yang penuh dengan sampah sudah menjadi hal yang biasa saja bagi masyarakat desa Kuta Jeumpa.

Dampak dari pembuangan sampah kedalam Sungai Putroe Aloh menyebabkan air sungai menjadi tercemar. Sementara masyarakat menggunakan air sungai tersebut untuk keperluan sehari-hari seperti mencuci, mandi, bahkan ada yang menggunakan air sungai untuk memasak nasi dan untuk diminum.
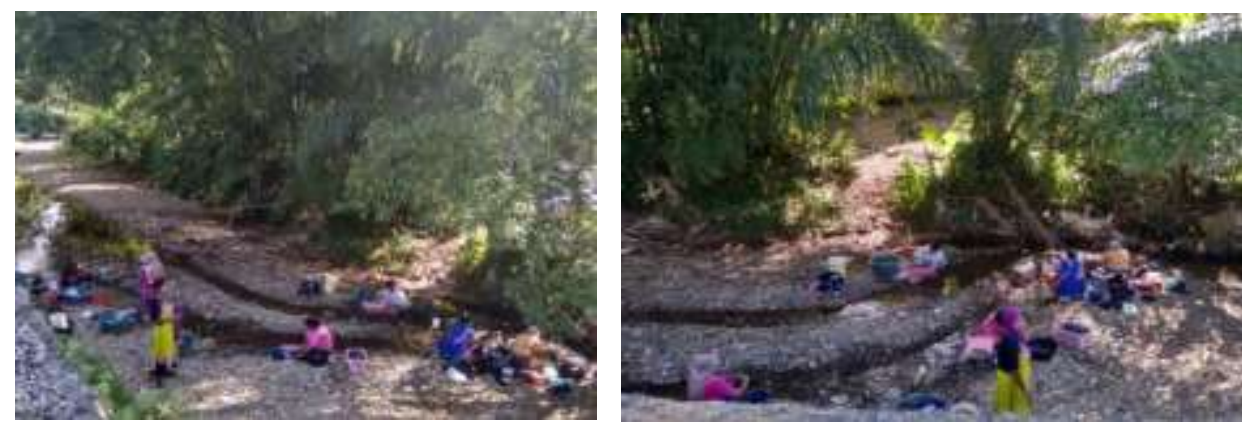

Gambar 2. Masyarakat menggunakan air sungai untuk keperluan sehari-hari

Gambar 2 menunjukkan masyarakat menggunakan air sungai Putroe Aloh untuk keperluan mencuci pakaian dan mandi. Padahal sungai tersebut sudah tercemar oleh sampah. Untuk mengatasi situasi tersebut, diperlukan edukasi terhadap warga kuta jeumpa untuk mengelola sampah dengan benar. Masyarakat desa Kuta Jeumpa perlu diberdayakan untuk menjadikan sampah menjadi sumber pendapatan.

\section{Tujuan Kegiatan}

Untuk memperkenalkan kepada masyarakat cara membuat produk makanan olahan dari sampah dan limbah rumah tangga.

\section{Manfaat Kegiatan}

Adapun manfaat dari kegiatan ini adalah :

1. Membantu masyarakat dalam pengelolaan sampah dan limbah rumah tangga.

2. Membantu masyarakat mendapatkan profit dari sampah dan limbah rumah tangga

3. Menanamkan nilai-nilai kebersihan kepada masyarakat agar tidak lagi membuang sampah ke sungai

4. Menumbuhkan sikap cinta bersih kepada masyarakat Desa Kuta Jeumpa.

Kurangnya sosialisasi tentang menjaga kebersihan lingkungan membuat masyarakat Desa Kuta Jeumpa kurang peduli terhadap lingkungan sekitar. Hardiatmi (2011) menyatakan permasalahan sampah di suatu kawasan meliputi tingginya laju timbulan sampah, kepedulian masyarakat yang masih rendah sehingga suka berperilaku membuang sampah sembarangan, keengganan untuk membuang sampah pada tempat yang sudah disediakan. Perilaku yang buruk ini seringkali menyebabkan bencana di musim hujan yang menyebabkan banjir.

Permasalahan sampah dimulai sejak meningkatnya jumlah manusia dan hewan penghasil sampah (Suyono dan Budiman, 2010). Membuang sampah ke aliran sungai juga akan menimbulkan berbagai macam gangguan kesehatan, membuat air sungai tercemar, dan menimbulkan bau menyengat keperkampungan. Untuk menghindari berbagai macam akibat yang ditimbulkan maka diperlukan upaya untuk mengajarkan dan memberdayakan masyarakat desa agar bisa mengelola sampah dan limbah rumah tangga menjadi produk yang bernilai ekonomis. 
Terdapat dua aspek dalam pengelolaan sampah, yaitu aspek teknis dan nonteknis. Aspek teknis terdiri atas pewadahan, pengumpulan sampah, pengangkutan sampah, pembuangan akhir, daur ulang, dan pengomposan. Sedangkan aspek nonteknis terdiri atas keuangan, institusi dan instansi pemerintah, partisipasi masyarakat, partisipasi pihak swasta, pungutan retribusi dan peraturan pemerintah (Nadiasa, dkk., 2009).

Pengelolaan sampah membutuhkan sejumlah tenaga, tergantung dari besar kecilnya permasalahan sampah yang dikelola (Sumantri A, 2013). Kebiasaan membuang sampah sembarangan dilakukan hampir di semua kalangan masyarakat, tidak hanya warga miskin, bahkan mereka yang berpendidikan tinggi juga melakukannya. Perilaku buruk ini semakin menjadi karena minimnya sarana kebersihan yang mudah dijangkau oleh masyarakat di tempat umum. Permasalahan sampah menjadi masalah yang belum terselesaikan dengan baik, khususnya di berbagai daerah di Indonesia. Jumlah sampah terus meningkat di setiap tahunnya. Kesadaran pemerintah dan masyarakat akan sampah harus digali agar terlepas dari permasalahan sampah (Geografic, 2016).

Partisipasi masyarakat dalam pengelolaan sampah merupakan aspek yang terpenting untuk diperhatikan dalam sis item pengelolaan sampah secara terpadu. Partisipasi masyarakat dalam suatu proses pembangunan terbagi atas 4 tahap, yaitu: a.) partisipasi pada tahap perencanaan, b.) partisipasi pada tahap pelaksanaan, c.) partisipasi pada tahap pemanfaatan hasil-hasil pembangunan dan d.) partisipasi dalam tahap pengawasan dan monitoring. Masyarakat senantiasa ikut partisipasi terhadap proses - proses pembangunan bila terdapat faktor - faktor yang mendukung, antara lain: kebutuhan, harapan, motivasi, ganjaran, kebutuhan sarana dan prasarana, dorongan moral, dan adanya kelembagaan baik informal maupun formal (Kusuma W, 2020). Mahyudin (2010) menemukan prioritas pengelolaan sampah yaitu strategi pemerintah, lingkungan dan persepsi masyarakat.

Talley (2013) merekomendasikan sistem pengelolaan sampah berbasis inisiatif komoditas lokal. Beberapa penelitian terdahulu telah membuktikan berbagai macam hasil olahan dari kulit jeruk, mulai dari manisan aneka rasa dan selai. Keterbatasan pengetahuan dan pengalaman masyarakat menjadi satu-satunya akar permasalahan dari terbuangnya potensi bisnis pengolahan limbah kulit jeruk. Oleh karena itu, dengan mendaur ulang limbah yang seharusnya dibuang menjadi suatu produk yang lebih berguna dan mempunyai nilai lebih menjadi kebutuhan sebagai salah satu alternatif usaha di tengah-tengah kelesuan berbisnis masyarakat (M Fadhil dan M Ashoer, 2019).

Bela (2021) melakukan pengabdian tentang pemanfaatan kulit manggis menjadi minuman tradisional di Desa Buat Kabupaten Bungo. Pengabdian yang dilakukan berhasil menambah pengetahuan masyarakat. Praptiningsih (2021) juga berhasil dalam melakukan pengabdian penanganan limbah baglog jamur tiram (Pleurotus Osteatus) di Desa Bodag Kecamatan Kare Kabupaten Madiun. Purnama (2021) melakukan pengabdian dengan tema daur ulang sampah di Desa Paisbuloli Sulawesi Tenggara. Salah satu olahan lainnya adalah dari kulit pisang. Kulit pisang merupakan limbah atau buangan buah pisang yang cukup banyak jumlahnya. Umumnya kulit pisang hanya dibuang dan tidak dimanfaatkan (Lubis, 2012). Kulit pisang bisa dijadikan manisan ataupun keripik kulit pisang.

\section{METODE}

Kegiatan ini dilakukan dengan metode pelatihan berupa pemaparan materi mengenai pemenfaatan limbah dan sisa makanan menjadi produk makanan olahan. Setelah dilakukan pemaparan materi oleh dosen, mahasiswa mempraktikka cara pembuatan produk makanan olahan dari limbah sisa makanan didepan masyarakat kuta jeumpa. Kegiatan pengabdian masyarakat ini dilakukan di kantor Keuchik Desa Kuta Jeumpa Kecamatan Jeumpa Kabupaten Aceh Barat Daya pada hari Minggu tanggal 29 Juli 2018. 
Adapun jumlah mahasiswa yang terlibat dalam kegiatan ini berjumlah 15 orang. 7 orang mahasiswa mempraktikkan pembuatan produk baru dari hasil pengolahan limbah makanan. 2 orang mahasiswa yang menjadi moderator yang membimbing masyarakat pada saat di praktikkan cara pengolahan limbah. Sisanya sebanyak 6 mahasiswa membantu penyediaan peralatan dan pengamanan.

Mahasiswa membuat pelatihan kepada masyarakat Desa Kuta Jeumpa cara mengolah limbah sisa makanan menjadi produk baru. Limbah sisa makanan tersebut adalah kulit jeruk, kulit buah naga, kulit semangka dan kulit pisang diolah menjadi manisan. Kulit pisang juga diolah menjadi kerupuk.

Target yang diharapkan dari pengabdian masyarakat ini adalah masyarakat Desa Kuta Jeumpa bisa mengelola sampah dengan baik. Masyarakat Desa Kuta Jeumpa bisa menghasilkan produk makanan dari limbah sisa makanan dan bisa untuk dijual. Target lainnya yang diharapkan masyarakat Desa Kuta Jeumpa tidak lagi membuang limbah sisa makanan kedalam sungai.

\section{HASIL DAN PEMBAHASAN}

Masyarakat yang hadir pada saat berlangsungnya kegiatan pengabdian masyarakat berjumlah 43 orang. Hampir $90 \%$ yang hadir adalah wanita, sementara sisanya adalah laki-laki. Pengabdian ini juga dihadiri oleh Keuchik Desa Kuta Jeumpa dan Sekretaris Desa. Kegiatan dilaksanakan selama satu hari. Pelaksanaan pengabdian diadakan sebanyak dua sesi, yaitu sesi pemberian materi dengan menggunakan Power Point dan sesi praktik pembuatan produk yang di bantu oleh mahasiswa.

Sesi pertama adalah pemberian materi tentang pengolahan limbah sisa makanan menjadi produk makanan olahan baru. Masyarakat sangat fokus mendengarkan materi yang disampaikan. Materi yang diberikan adalah tentang pengolahan kulit jeruk, kulit buah naga, dan kulit papaya menjadi produk makanan baru yang bisa dijual dan dipasarkan. Pada saat selesai diberikan materi, banyak masyarakat yang bertanya tentang cara pengolahan limbah-limbah tersebut. Agar masyarakat bisa lebih paham tentang materi yang diberikan, maka dilakukanlah praktek pembuatan langsung pada sesi 2 .

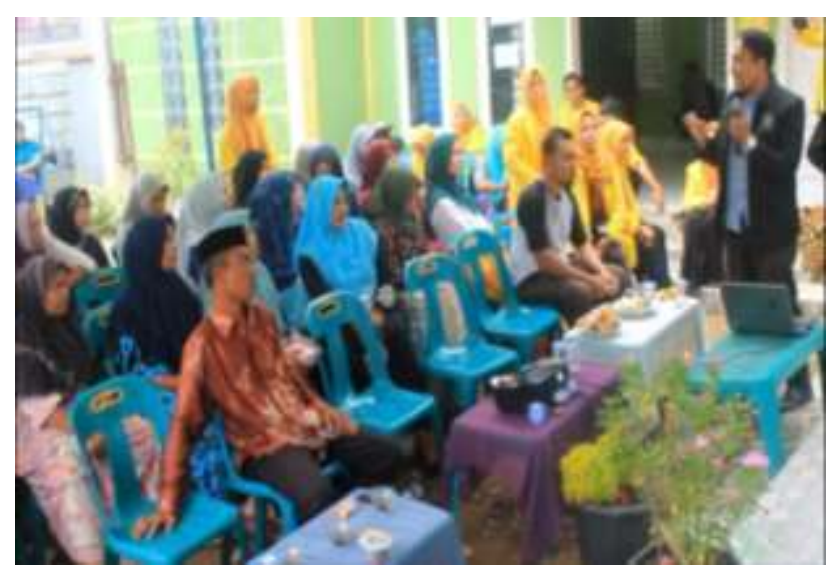

Gambar 3. Penyampaian Materi Kepada Masyarakat

Masyarakat sangat antusias dengan materi yang telah dipaparkan. Selain cara pengolahan limbah, banyak dari masyarakat yang bertanya bagaimana caranya agar produk yang telah dibuat bisa laku dijual nantinya. Untuk menjawab pertanyaan dari masyarakat, pemateri banyak memberikan cara untuk promosi dan cara untuk memilh strategi pemasaran, serta memberikan contoh nyata masyarakat yang telah berhasil mengolah sampah menjadi produk yang menguntungkan. 
Setelah pemaparan materi dan tanya jawab selesai, kemudian dilakukan praktek langsung yang dilakukan oleh mahasiswa yaitu membuat manisan dari kulit jeruk, manisan kulit buah naga, dan pembuatan abon kulit pepaya. Pada saat dilakukan praktek, masyarakat ikut dilibatkan untuk membuat dan melihat secara langsung proses pembuatan produk olahan makanan tersebut.
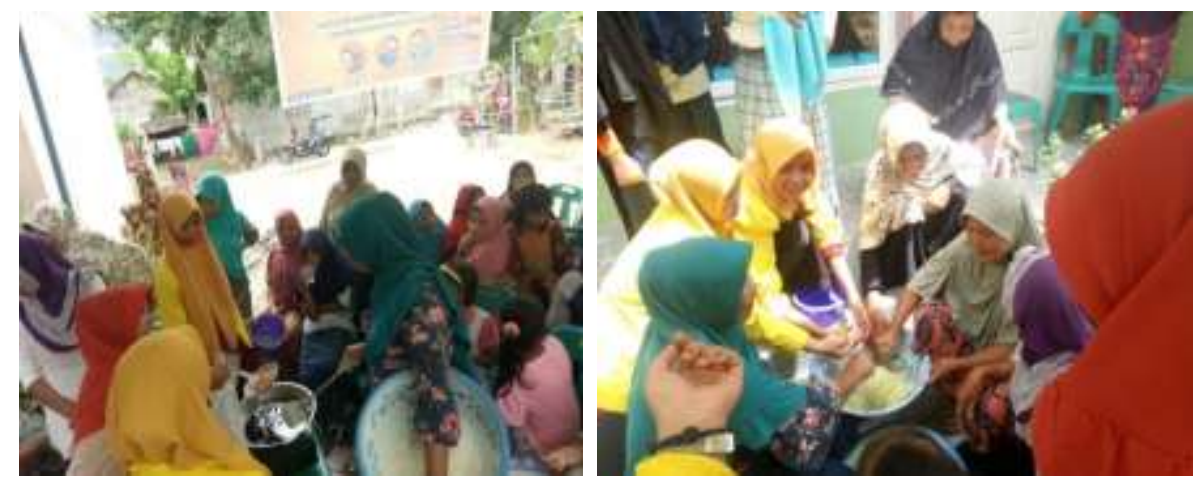

Gambar 4. Praktik pembutan produk makanan olahan baru dari limbah sisa makanan

Semua masyarakat terlibat pada saat dilakukan praktek pembuatan manisan dari kulit jeruk, manisan kulit buah naga, dan pembuatan abon kulit papaya. Mahasiswa memberikan bimbingan langsung dalam praktek tersebut. Praktek dilakukan sampai masyarakat bisa menghasilkan produk manisan dari kulit jeruk, manisan kulit buah naga dan abon kulit papaya.

\section{Respon dan Tanggapan Khalayak Sasaran}

Masyarakat menyambut semua materi yang diberikan dengan sangat antusias, hal ini dapat dilihat dari jumlah masyarakat yang hadir sebanyak 43 orang. Kemampuan peserta dalam memahami materi cukup baik, terlihat dari produk yang dihasilkan oleh peserta yang di bimbing oleh mahasiswa dan dosen.
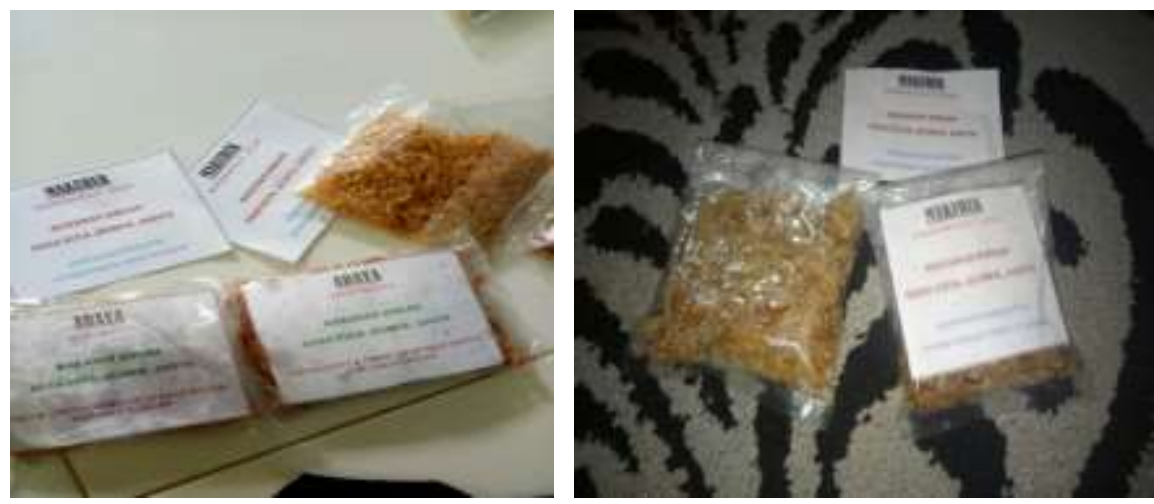

Gambar 5. Produk makanan olahan yang dihasilkan

\section{Hasil Evaluasi}

Evaluasi dilakukan dengan melihat pemahaman masyarakat terhadap hasil produk makanan olahan yang di buat oleh masyarakat. Produk olahan makanan tersebut sangat bagus dan bisa untuk dijual dan dipasarkan kepada konsumen. Masyarakat mempunyai dorongan untuk memproduksi produk dari limbah tersebut dan tidak lagi membuang sampah di sungai. 


\section{KESIMPULAN}

Masyarakat Kuta Jeumpa berhasil membuat produk baru dari hasil olahan limbah makanan yang dibimbing oleh mahasiswa bersama dosen. Produk tersebut antara lain manisan dari kulit jeruk, manisan kulit buah naga, dan abon kulit papaya. Produk yang dihasilkan tersebut bisa memberikan nilai profit bagi masyarakat. Masyarakat juga teredukasi tidak lagi membuang sampah ke sungai.

\section{DAFTAR PUSTAKA}

Bela Putra. 2021. Pemanfaatan Kulit Manggis Menjadi Minuman Tradisional di Desa Buat Kabupaten Bungo. DINAMISIA: Jurnal Pengabdian Kepada Masyarakat. Vol. 5, No. 1 Februari 2021, Hal. 60-64.

Geografic, N. (2016). Indonesia Darurat Sampah . Indonesia darurat sampah. http://nationalgeografic.co.id/berita/2016/01/indonesia-darurat-sampah. diakses pada tanggal 14 September 2020.

Hardiatmi, S. 2011. Pendukung Keberhasilan Pengelolaan Sampah Kota. INNOFARM. Jurnal Inovasi Pertanian, 10(1): 50-66.

Kale SS, Kadam AK, Kumar S, Pawar NJ. 2010. Evaluating Polluting Potential Of Leachate From Landfill site, from the pune metropolitan city and its impact to shallow basaltic aquifers. Everon Monit Assess. 162: 327-346.

Kusuma Wardany, Reni Permata Sari, Erni Mariana. 2020. Sosialisasi Pendirian "Bank Sampah" Bagi Peningkatan Pendapatan Dan Pemberdayaan Perempuan Di Margasari. DINAMISIA: Jurnal Pengabdian Kepada Masyarakat. Vol. 4, No. 2 Juni 2020, Hal. 364-372.

Lubis Z. 2012. Pengaruh Penambahan Tepung Kulit Pisang Raja (Musa Paradisiaca) Terhadap Daya Terima Kue Donat. Universitas Sumatera Utara.

Mahyudin RP. 2010. Strategi Pengelolaan Sampah Berkelanjutan. EnviroScentiae, 10 : 33-40.

M Fadhil dan M Ashoer, 2019. Usaha Manisan Aneka Rasa Melalui Pemanfaatan Kulit Jeruk Pamelo Di Desa Padanglampe Kabupaten Pangkep. Buletin Udayana Mengabdi. Volume 18 Nomor 3, Juli 2019.

Nadiasa, M., Sudarsana, D.K., Yasmara, I.N. 2009. Manajemen Pengangkutan Sampah Di Kota Amlapura. Jurnal Ilmiah Teknik Sipil, 13 (2) : 120-135.

Praptiningsih Gamawati Adinurani. Sri Rahayu. 2021. Penanganan Limbah Baglog Jamur Tiram (Pleurotus osteatus)di Desa Bodag Kecamatan Kare Kabupaten Madiun. DINAMISIA: Jurnal Pengabdian Kepada Masyarakat. Vol. 5, No. 1 Februari 2021, Hal. 206-213.

Purnama Pasande, Ezra Tari. 2021. Daur Ulang Sampah di Desa Paisbuloli Sulawesi Tenggara. DINAMISIA: Jurnal Pengabdian Kepada Masyarakat. Vol. 5, No. 1 Februari 2021, Hal. 147-153.

Suyono \& Budiman. 2010. Ilmu Kesehatan Masyarakat Dalam Kontek Kesehatan Lingkungan. Jakarta: EGC.

Sumantri A. 2013. Kesehatan Lingkungan. Jakarta:Kencana Prenada Media Grup 